\title{
Commentary \\ Predictive factor for the response to adjuvant therapy with emphasis in breast cancer
}

Pamela N Munster* and Larry Norton ${ }^{\dagger}$

*H Lee Moffitt Cancer Center and Research Institute, Tampa, Florida, USA

${ }^{\dagger}$ Memorial Sloan-Kettering Cancer Center, New York, New York, USA

Correspondence: Pamela N Munster, Comprehensive Breast Program, H Lee Moffitt Cancer Center and Research Institute, MRC 3E, 12902 Magnolia Drive, Tampa, FL 33612, USA. Tel: +1 813903 6893; fax: +1 813903 6817; e-mail: Munstepn@moffitt.usf.edu

Received: 9 May 2001

Breast Cancer Res 2001, 3:361-364

Revisions requested: 11 June 2001

Revisions received: 13 August 2001

Accepted: 13 September 2001

Published: 1 October 2001
(C) 2001 BioMed Central Ltd

(Print ISSN 1465-5411; Online ISSN 1465-542X)

\begin{abstract}
One of the major challenges of early-stage breast cancer is to select the adjuvant therapy that ensures the most benefits and the least harm for the patient. The definition of accurate predictive factors is therefore of paramount importance. So far the choice of adjuvant therapy has been based on the number of affected lymph nodes and the hormone receptor status of the patient. This paper evaluates the use of other tumor-related markers as predictive factors for adjuvant therapy. These include HER2, p53 and Bcl-2, cathepsin B, p27, proliferating cell nuclear antigen (PCNA), cyclin D, Ki-67, and vascular endothelial growth factor (VEGF).
\end{abstract}

Keywords: adjuvant therapy, breast cancer, predictive factors

\section{Introduction}

The definition of accurate markers in response to adjuvant chemotherapy to select the appropriate adjuvant therapy would immensely improve efficacy and would avoid unnecessary toxicity and long-term sequelae in those patients not responsive to the selected adjuvant chemotherapy.

So far, the strongest predictive and prognostic factor has been the number of affected lymph nodes. However, the clinical outcome remains unpredictable in spite of effective adjuvant therapy. Many investigators have therefore focused on finding molecular markers that may predict prognosis and response to therapy. When evaluating a molecular marker as a predicting factor, two aspects have to be taken into account. One is the likelihood of response to agents that target and modulate this particular marker, the other is the accuracy with which its absence or presence predicts for response to current standard therapy. It is well established that the expression of the estrogen receptor (ER) or the progesterone receptor $(\mathrm{PR})$ determines the responsiveness of tumors to hormonal interventions; nevertheless the absence or presence of these hormone receptors does not predict the response to chemotherapy.

Of the many molecular markers that have been studied, we shall focus on HER-2/neu (HER2, c-erbB2, p185), p53 and Bcl-2. Others markers of interest are cathepsin $\mathrm{B}$, Retinoblastoma, p27, proliferating cell nuclear antigen (PCNA), cyclin D, Ki-67, and vascular endothelial growth factor (VEGF). Although their role as prognostic factors is being evaluated, very little is known about their predictive value.

NSABP $=$ National Surgical Adjuvant Breast and Bowel Project

$\mathrm{AC}=$ doxorubicin, cyclophosphamide; $\mathrm{CAF}=$ cyclophosphamide, doxorubicin, 5-fluorouracil; CMF = cyclophosphamide, methotrexate, 5-fluorouracil; $\mathrm{ER}=$ estrogen receptor; $\mathrm{FISH}=$ fluorescence in situ hybridization; PCNA = proliferating cell nuclear antigen; $\mathrm{PR}=$ progesterone receptor; VEGF $=$ vascular endothelial growth factor. 


\section{C-erbB2/HER-2/neu}

One of the most interesting molecular markers currently being studied is HER-2/neu. The neu proto-oncogene encodes a receptor tyrosine kinase of the HER kinase family. Amplification and overexpression of this oncogene is seen in $25-30 \%$ of breast cancers and is associated with a poor prognosis [1]; however, this is limited to nodepositive disease. The level of gene amplification or expression of HER-2/neu undoubtedly determines the response to trastuzumab (Herceptin ${ }^{\mathrm{TM}}$ ), a monoclonal antibody directed against HER-2/neu receptor. Only tumors with $3+$ protein expression or gene amplification are likely to benefit from this type of therapy. However, several studies have addressed the role of HER-2/neu in predicting the response to chemotherapy.

In a large study performed by the National Surgical Adjuvant Breast and Bowel Project (NSABP) (B-11), patients with node-positive, ER-negative tumors were treated with phenylalanine-mustard and 5-fluorouracil with or without doxorubicin. The interaction between the overexpression of HER-2/neu and doxorubicin was significant for diseasefree survival but not for overall survival [2]. A second study performed by the NSABP (B-15) compared the response to adjuvant therapy with $\mathrm{AC}$ (doxorubicin, cyclophosphamide) with that to CMF (cyclophosphamide, methotrexate, 5-fluorouracil) in tumors with either high or low expression of HER-2/neu. In this study, AC was superior only in patients with HER-2/neu-positive tumors; however, the analysis did not reach statistical significance [3].

A trial performed by the Cancer and Leukemia Group B (CALGB 8541) compared three doses of doxorubicin (high, moderate, and low) in the CAF regimen (cyclophosphamide, doxorubicin, 5-fluorouracil) in women with nodepositive breast cancer. Patients whose tumors showed high expression of HER-2/neu had significantly longer disease-free survival and overall survival when treated with moderate or high doses of doxorubicin [4]. This study was then re-evaluated after a longer follow-up period and with further patients. The interaction between CAF and HER$2 / n e u$ in the original set of patients remained significant with a longer follow-up. However, in the group of patients added later there was only a trend towards a benefit with anthracycline-based therapy, but this did not reach statistical significance without adjustment for other prognostic factors [5].

Another study presented at the American Society of Clinical Oncology (ASCO) meeting in 1998 evaluated the predictive value of HER-2/neu in a subset of patients with ER-positive, node-positive tumors. Although the patients whose tumors overexpressed HER-2/neu seemed to benefit from adjuvant chemotherapy, an interaction between HER-2/neu and adjuvant CAF chemotherapy by statistical analysis could not be demonstrated clearly [6].
Considering all the data available, the use of anthracyclines in HER-2/neu-positive tumors with high expression was addressed at the $\mathrm{NIH}$ consensus meeting in November 2000. The conclusion of this meeting was not to consider HER-2/neu as a predictor of response to anthracyclines [7].

Although some of these studies clearly suggest that patients whose tumors overexpress HER-2/neu might benefit from anthracyclines, other studies did not confirm these findings. One of the main reasons for the discrepancy of these results lies in the tests used in these studies. Many of the studies were performed by using immunohistochemistry with different antibodies, some of which are now considered inaccurate. More recent data suggest that fluorescence in situ hybridization (FISH) analysis of the amplified gene is probably the most reliable and predictable test. The correlation between FISH and many of the antibodies used is only about $80 \%$. This is higher than $80 \%$ for $3+$ protein expression, but is probably lower for $2+$ protein expression. Many of the studies will therefore have to be reanalyzed for FISH or for more uniform immunohistochemistry assays. The results are further confounded by the fact that most of these studies were retrospective analyses and the randomization was not stratified for HER-2/neu overexpression.

In summary, it is important to define the value of HER$2 /$ neu stratification as a predictor of response. So far there has not been enough evidence to support the use of anthracyclines in all node-positive patients whose tumors overexpress HER-2/neu. Nevertheless, anthracyclinebased therapy is effective and showed a small but significant increase in disease-free survival as demonstrated by the Oxford overview in 1998 [8] in the population of nodepositive patients as a whole. Future studies should establish whether most of the effects of anthracycline-based chemotherapy are confined to this group.

\section{p53}

The p53 tumor suppressor gene is located on the short arm of chromosome 17. Expression of mutant p53 is the most common genetic defect in human cancers and occurs in about $20 \%$ of sporadic syndromes, $50 \%$ of familial syndromes and in all cases of Li-Fraumeni syndromes. Mutations in the $p 53$ gene lead to an accumulation of nuclear p53 protein [9].

Functional $p 53$ is required for cell cycle regulation and for the induction of apoptosis. Preclinical data have shown that cells with mutated p53 might be resistant to certain types of apoptotic stimuli such as radiation and chemotherapeutics [10].

Although in many univariant analyses $p 53$ is associated with a poor overall survival, this is often not supported 
when analyzed as an independent factor. Expression of mutant $p 53$ is frequently associated with lack of ER expression and a high proliferation rate. Furthermore, technical difficulties and variability in the assays used often render their assessment difficult.

Several clinical trials have not shown any predictive value for $p 53$ in women with either node-positive or node-negative breast cancer receiving CMF [11-15].

The role of $p 53$ as a predictive marker to anthracyclinebased therapy is more complex. Overexpression of $p 53$ conveyed poor response to one perioperative course of 5 fluorouracil, doxorubicin and cyclophosphamide (FAC) in women with node-negative breast cancer [16]. However, this was not seen in women with node-positive breast cancer treated with three cycles of CAF [4].

In patients treated with epirubicin, mutant $p 53$ predicted significantly poorer response to neo-adjuvant therapy [15] and poorer disease-free and overall survival after adjuvant therapy in patients with node-positive breast cancer [17]. However, although these findings might suggest a role of p53 as a negative predictor of response to anthracyclines, more data are needed to confirm these results.

Few studies have focused on the predictive value of $p 53$ and sensitivity to taxane. Preclinical data have suggested that a loss of $p 53$ confers sensitivity to taxanes $[18,19]$. However, this has not been supported by clinical studies and the absence or presence of $p 53$ cannot be used to determine the need for taxanes in the adjuvant setiing [20].

\section{$\mathrm{BCl}-2$}

Members of the Bcl-2 family are mitochondrial proteins that regulate programmed cell death. By forming various homodimers and heterodimers they either promote or inhibit apoptosis. Bcl-2 inhibits the release of cytochrome $c$ from the mitochondria and thus prevents the activation of Apaf-1 and subsequently the caspase pathways [21]. Overexpression of Bcl-2 has been associated with resistance to apoptotic stimuli in several tumors. In breast cancer, expression of $\mathrm{Bcl}-2$ has been associated with expression of ER and low proliferation rate; however, it has not been an independently prognostic factor [22].

Only a few studies are available to assess $\mathrm{Bcl}-2$ as a predictive factor. The expression of $\mathrm{Bcl}-2$ did not influence the outcome of perioperative chemotherapy with CAF in premenopausal patients with lymph-node-negative breast cancers [23]. In contrast, one study showed that overexpression of $\mathrm{Bcl}-2$ was associated with significantly better overall survival in patients treated with adjuvant CMF [11]. Results from a study in women treated with adjuvant therapy by using epirubicin and cyclophosphamide showed that the expression of $\mathrm{Bcl}-2$ was associated with better disease-free survival and overall survival, but only in lobular carcinoma, not in ductal carcinoma [17].

The data available are insufficient for definitive conclusions to be drawn about the role of $\mathrm{Bcl}-2$ as a predictive factor.

\section{Other investigational markers}

Of interest are other molecular markers that might be targets of directed therapy, such as VEGF. Many trials are evaluating inhibitors of VEGF or VEGF receptor as potential therapeutic agents. So far no clear correlation between VEGF expression and response to VEGF inhibitors has been established. A recent report has suggested that lowexpression VEGF might be an independent predictor for response to endocrine therapy but not to adjuvant chemotherapy [24].

Insufficient data are available to suggest a role for cathep$\sin \mathrm{B}$, Retinoblastoma, p27, PCNA, cyclin D, or Ki-67 as predictors of response to chemotherapy.

\section{Conclusion}

In spite of the fact that many studies have addressed the use of molecular markers as predictive factors for chemotherapy, the data remain controversial and inconclusive. Anthracyclines are effective therapy for breast cancer regardless of HER-2 status, but patients whose tumors overexpress HER-2 seem to derive the greatest relative benefit from this therapy. Studies of HER-2 as a predictor of response to CMF and to radiotherapy are as yet inconclusive. On the basis of the currently available data, p53 and $\mathrm{Bcl}-2$ cannot be used to select a specific type of adjuvant therapy, and insufficient data are available for cathep$\sin \mathrm{B}, \mathrm{p} 27, \mathrm{PCNA}$, cyclin D, Ki-67 and VEGF.

\section{References}

1. Slamon DJ, Clark GM, Wong SG, Levin WJ, Ullrich A, McGuire WL: Human breast cancer: correlation of relapse and survival with amplification of the HER-2/neu oncogene. Science 1987, 235:177-182.

2. Paik S, Bryant J, Park C, Fisher B, Tan-Chiu E, Hyams D, Fisher ER, Lippman ME, Wickerham DL, Wolmark N: erbB-2 and response to doxorubicin in patients with axillary lymph nodepositive, hormone receptor-negative breast cancer. J Natl Cancer Inst 1998, 90:1361-1370.

3. Paik S, Bryant J, Tan-Chiu E, Yothers G, Park C, Wickerham DL, Wolmark N: HER2 and choice of adjuvant chemotherapy for invasive breast cancer: National Surgical Adjuvant Breast and Bowel Project Protocol B-15. J Natl Cancer Inst 2000, 92: 1991-1998.

4. Muss HB, Thor AD, Berry DA, Kute T, Liu ET, Koerner F, Cirrincione CT, Budman DR, Wood WC, Barcos M: c-erbB-2 expression and response to adjuvant therapy in women with node-positive early breast cancer. $N$ Engl J Med 1994, 330: 1260-1266. (Erratum, 331:211.)

5. Thor AD, Berry DA, Budman DR, Muss HB, Kute T, Henderson IC, Barcos M, Cirrincione C, Edgerton S, Allred C, Norton L, Liu ET: erbB-2, p53, and efficacy of adjuvant therapy in lymph nodepositive breast cancer. J Natl Cancer Inst 1998, 90:1346-1360.

6. Ravdin PM, Green S, K.S. Albain KS, Ingle J, Pritchard K, Shepard L, Davidson N, Hayes D, Clark G, Martino S, Osborne C, Allred D: Initial Report of the SWOG Biological Correlative Study of cerbb-2 Expression as a Predictor of Outcome in a Trial Com- 
paring Adjuvant CAFT with Tamoxifen ( $\mathrm{T}$ ) alone [abstract]. Proc Am Soc Clin Oncol 1998, A374.

7. Sledge G: Is HER-2/neu a predictor of anthracycline utility? No. http://odp.od.nih.gov/consensus/cons/114/114_intro.htm 2000: 75.

8. Early Breast Cancer Trialists' Group: Polychemotherapy for early breast cancer: an overview of the randomised trials. Early Breast Cancer Trialists' Collaborative Group. Lancet 1998, 352:930-942.

9. Thor AD, Moore DH, II, Edgerton SM, Kawasaki ES, Reihsaus E, Lynch HT, Marcus JN, Schwartz L, Chen LC, Mayall BH: Accumulation of p53 tumor suppressor gene protein: an independent marker of prognosis in breast cancers. J Natl Cancer Inst 1992, 84:845-855.

10. Lowe SW, Ruley HE, Jacks T, Housman DE: p53-dependent apoptosis modulates the cytotoxicity of anticancer agents. Cell 1993, 74:957-967.

11. Gasparini G, Barbareschi M, Doglioni C, Palma PD, Mauri FA, Boracchi P, Bevilacqua P, Caffo O, Morelli L, Verderio P: Expression of bcl-2 protein predicts efficacy of adjuvant treatments in operable node-positive breast cancer. Clin Cancer Res 1995, 1:189-198.

12. Dublin EA, Miles DW, Rubens RD, Smith P, Barnes DM: p53 immunohistochemical staining and survival after adjuvant chemotherapy for breast cancer. Int J Cancer 1997, 74:605-608.

13. Veronese S, Mauri FA, Caffo O, Scaioli M, Aldovini D, Perrone G, Galligioni E, Doglioni C, Dalla Palma P, Barbareschi M: Bax immunohistochemical expression in breast carcinoma: a study with long term follow-up. Int J Cancer 1998, 79:13-18.

14. Degeorges A, de Roquancourt A, Extra JM, Espie M, Bourstyn E, de Cremoux P, Soussi T, Marty M: Is p53 a protein that predicts the response to chemotherapy in node negative breast cancer? Breast Cancer Res Treat 1998, 47:47-55.

15. Bottini A, Berruti A, Bersiga A, Brizzi MP, Brunelli A, Gorzegno G, DiMarco B, Aguggini S, Bolsi G, Cirillo F, Filippini L, Betri E, Bertoli $G$, Alquati $P$, Dogliotti L: p53 but not bcl-2 immunostaining is predictive of poor clinical complete response to primary chemotherapy in breast cancer patients. Clin Cancer Res 2000, 6:2751-2758.

16. Clahsen PC, van de Velde CJ, Duval C, Pallud C, Mandard AM, Delobelle-Deroide A, van den Broek L, Sahmoud TM, van de Vijver MJ: p53 protein accumulation and response to adjuvant chemotherapy in premenopausal women with node-negative early breast cancer. J Clin Oncol 1998, 16:470-479.

17. Mottolese M, Benevolo M, Del Monte G, Buglioni S, Papaldo P, Nistico C, Di Filippo F, Vasselli S, Vici P, Botti C: Role of P53 and $\mathrm{BCL}-2$ in high-risk breast cancer patients treated with adjuvant anthracycline-based chemotherapy. J Cancer Res Clin Oncol 2000, 126:722-729.

18. Zhang CC, Yang JM, Bash-Babula J, White E, Murphy M, Levine AJ, Hait WN: DNA damage increases sensitivity to vinca alkaloids and decreases sensitivity to taxanes through p53dependent repression of microtubule-associated protein 4. Cancer Res 1999, 59:3663-3670.

19. Wahl AF, Donaldson KL, Fairchild C, Lee FY, Foster SA, Demers GW, Galloway DA: Loss of normal p53 function confers sensitization to Taxol by increasing G2/M arrest and apoptosis. Nat Med 1996, 2:72-79.

20. Sjostrom J, Blomqvist C, Heikkila P, Boguslawski KV, RaisanenSokolowski A, Bengtsson NO, Mjaaland I, Malmstrom P, Ostenstadt B, Bergh J, Wist E, Valvere V, Saksela E: Predictive value of p53, mdm-2, p21, and mib-1 for chemotherapy response in advanced breast cancer. Clin Cancer Res 2000, 6:3103-3110.

21. Eskes R, Antonsson B, Osen-Sand A, Montessuit S, Richter C Sadoul R, Mazzei G, Nichols A, Martinou JC: Bax-induced cytochrome $C$ release from mitochondria is independent of the permeability transition pore but highly dependent on $\mathbf{M g}^{2+}$ ions. J Cell Biol 1998, 143:217-224.

22. Hellemans P, van Dam PA, Weyler J, van Oosterom AT, Buytaert $P$, Van Marck E: Prognostic value of bcl-2 expression in invasive breast cancer. Br J Cancer 1995, 72:354-360.

23. van Slooten $\mathrm{HJ}$, Clahsen PC, van Dierendonck JH, Duval C, Pallud C, Mandard AM, Delobelle-Deroide A, van de Velde CJ, van de Vijver MJ: Expression of $\mathrm{Bcl}-2$ in node-negative breast cancer is associated with various prognostic factors, but does not predict response to one course of perioperative chemotherapy. Br J Cancer 1996, 74:78-85.
24. Linderholm B, Grankvist K, Wilking N, Johansson M, Tavelin B, Henriksson R: Correlation of vascular endothelial growth factor content with recurrences, survival, and first relapse site in primary node-positive breast carcinoma after adjuvant treatment. J Clin Oncol 2000, 18:1423-1431. 